\title{
Evaluation of the Effectiveness of Video Assisted Teaching (VAT) on Knowl- edge and Practice of Dental Hygiene in Bangalore's Primary Schools
}

\author{
Christine Nyirahabimana \\ Institut Superieur Pedagogique de Gitwe, Rwanda
}

\section{Background and Aim}

The aim of this study was to evaluate the effectiveness of Video Assisted Teaching (VAT) on the knowledge and practice of dental hygiene among primary school children in Bangalore, India. The hypothesis to be tested was that the mean post-test knowledge and practice scores of primary school children exposed to VAT on dental hygiene may be more than their mean pretest knowledge and practice scores at 0.05 level of significance.

\section{Methodology}

A quantitative approach and pre- and post-experimental design was selected for this study conducted during November 2011 at Sheshadripuram and Jnana Jyothi Schools, Bangalore, India. The sample size of 50 children was selected to assess the effectiveness of VAT. The purposive sampling technique was used to select the sample. In pretest, data were collected using questionnaire and observational check-list, and then VAT was administered. After 8 days, the post test was given. Data collected were analyzed using descriptive and inferential statistics (Paired $\mathbf{t}$ test).

\section{Results}

Evaluation of the pretest knowledge scores demonstrated that $46 \%$ of children had moderately adequate knowledge, only $20 \%$ had adequate knowledge, and100\% exhibited inadequate practice level regarding dental hygiene. After VAT, $100 \%$ of children exhibited adequate knowledge and practice regarding dental hygiene. The $t$ - test showed that there was significant improvement in the post-test knowledge and practice scores on dental hygiene with $t$ value of 11.65 at $\mathrm{p}<0.05$ level i.e. $95 \%$.

These results have crucial implications in nursing profession and evidence based practice, identifying teaching needs in community settings. In fact, among extended and expanded roles of nurse, education is included, and it should emphasize on the needs for health promotion and diseases prevention, utilizing modern methods of educational technology, such as Video Assisted Teaching (VAT).

\section{Conclusion}

The VAT was found to be effective in improving knowledge and practice of primary school children in the area of dental hygiene.Through this successful study, the hypothesis stating that VAT would improve dental hygiene was confirmed at $95 \%$.

Key words: educational technology, video assisted teaching, health promotion, evidence based practice, dental hygiene 